\title{
Sustentabilidade Financeira das Instituições de Microfinanças Brasileiras: Análise das Cooperativas de Crédito Singulares
}

\author{
Edison Luiz Leismann ${ }^{1}$ \\ Charles Ulises de Montreuil Carmona ${ }^{2}$
}

\begin{abstract}
Resumo: Este trabalho tem por objetivo analisar a sustentabilidade financeira das Cooperativas de Crédito Singulares do Brasil. A análise dos dados financeiros das cooperativas de crédito, Sociedades de Crédito ao Microempreendedor (SCM) e crédito mútuo compõem o objeto de estudo. A análise foi realizada a partir dos dados de 31/12/2007 disponibilizados pelo Banco Central de 1.439 instituições. Com dados adicionais de 31 instituições liquidadas entre 2003 e 2006, totalizaram-se 1.470 instituições analisadas. Com os valores originais, o banco de dados foi dividido aleatoriamente em duas partes, cada qual com 735 instituições, sendo o primeiro denominado de amostra de desenvolvimento e o segundo, de amostra de validação. A avaliação principal foi feita a partir da Análise Discriminante com os dados obtidos e com padronização. Outras abordagens foram desenvolvidas e comparadas. Os resultados mostram que a segunda abordagem, com padronização e subdivisão das instituições por tamanho (valor do ativo) permite obter resultados mais aprimorados, com Correlação Canônica de 0,994, mostrando que a variável dependente pode ser explicada em 98,8\% pelas variáveis independentes. Desta forma, as análises mostram a funcionalidade dessas abordagens como instrumento de classificação, servindo como mecanismo de auxílio aos órgãos reguladores e Cooperativas Centrais no acompanhamento das unidades singulares.
\end{abstract}

\footnotetext{
1 Professor Associado do Centro de Ciências Sociais Aplicadas da Unioeste. Pós Doutor em Administração pela UFPE-PE. E-mail: elleismann@gmail.com

2 Professor Adjunto do Departamento de Ciências Administrativas e do Programa de Pósgraduação em Administração da Universidade Federal de Pernambuco (Propad/UFPE). Doutor em Engenharia da Produção, PUC/RJ. E-mail: carmona@ufpe.br
} 
636 - Sustentabilidade Financeira das Instituições de Microfinanças Brasileiras: Análise das Cooperativas de Crédito Singulares

Palavras-chaves: Cooperativas de crédito, sustentabilidade financeira, análise discriminante.

Abstract: This work aims to analyze the financial sustainability of Single Credit Cooperatives of Brazil. The analysis of financial data from credit cooperatives, credit societies of Small Entrepreneur (SCM) and credit make up the mutual object of study. The analysis was performed from the data available from 2007/12/31 by the Central Bank of Brazil of 1,439 institutions. We used indicators of financial structure, assets and the statements of results of those institutions. With additional data from 31 institutions presented between 2003 and 2006, the total is 1,470 institutions analyzed. With the original values, database was divided randomly into two parts, each one with 735 institutions, and the first known sample of development and the second called the validation sample. Other approaches have been developed. The main evaluation was made from the Discriminant Analysis. The results show that the alternative approach with subdivision of standardization and institutions by size (value of assets) to obtain more refined results. Thus, the analysis shows the functionality of these approaches as a tool for classification, serving as a mechanism to help regulatory agencies and the Cooperative Central monitoring of natural units.

Key-words: Credit cooperatives, financial sustainability, discriminant analysis.

Classificação JEL: M41.

\section{Introdução}

Embora os estudos e acompanhamentos dos órgãos reguladores quanto aos aspectos relacionados à sustentabilidade financeira das instituições não sejam recentes, sendo objeto de preocupação internacional, tornaram-se mais importantes a partir da crise econômica mundial deflagrada em 2007/2008.

Conforme afirmado por Dallara, em Resenha BMF 176 (2009, p. 52), "o ponto central da crise a que assistimos em algumas companhias referese ao controle de risco. Os responsáveis por esse trabalho nas empresas têm a grande tarefa de implementar estratégica e taticamente ações que construam uma boa cultura de risco".

Os acordos da Basiléia I e II foram estabelecidos em função da preocupação com os riscos envolvendo as instituições financeiras. O primeiro 


\section{Edison Luiz Leismann \&

foi estabelecido em 1988, embora o Comitê da Basiléia tenha sido criado na década de 70 , com a preocupação quanto ao crescimento das operações bancárias internacionais e o segundo, estabelecido em 2004, com a preocupação relacionada aos riscos operacionais (BIS (2009)). Embora não sejam obrigatórios, têm sido adotados pela maioria dos países, inclusive no Brasil. Como mostram Hoffman \& Drumond de Melo (2006), as "normas prudenciais estão em linha com os padrões internacionais e desenvolvem a cultura de administração de riscos (...) e as normas atuais incentivam a criação de modelos proprietários para avaliação do risco de crédito e disciplina de mercado".

Com relação ao acordo de Basiléia II, afirmam Carvalho \& Caldas (2006, p. 79), este "procura minimizar os problemas resultantes da padronização imposta por regras gerais, reconhecendo a possibilidade de as instituições financeiras optarem por desenhos mais próximos de suas exposições particulares". Em síntese,

A nova estrutura é construída sobre três pilares: Pilar 1 - Requerimentos mínimos de capital; Pilar 2 - Processo de revisão de supervisão; Pilar 3 - Disciplina de mercado. Na prática, as diferenças substanciais entre Basiléia I e II são estruturais, a saber: - nas duas versões, as instituições financeiras devem ter capital suficiente para fazer frente aos riscos que reconhecem e resolvem correr em função de o trade-off risco/retorno ser favorável (dimensão da alocação de capital, Pilar 1); - Basiléia II acrescenta, em função da decisão anterior, que a adoção de boas práticas de gerenciamento de riscos pelos bancos deve ser verificada pelos reguladores (dimensão da supervisão bancária, Pilar 2); - Basiléia II acrescenta também a necessidade de demonstração efetiva, por parte das instituições, de transparência e melhor comunicação com o mercado em que atua (dimensão do disclousure, Pilar 3) (CARVALHO \& CALDAS (2006, p. 79).

Todavia, embora as preocupações sejam recorrentes envolvendo o risco das instituições financeiras, a crise econômica recente, intensificada a partir da quebra de importantes bancos, fez com que as discussões sobre regulação e acompanhamento das instituições financeiras se ampliassem. Em recente documento divulgado pelo BIS (2009, p. 7), são ressaltadas essas necessidades. 
638 - Sustentabilidade Financeira das Instituições de Microfinanças Brasileiras: Análise das Cooperativas de Crédito Singulares

Afirma o documento que "é igualmente importante que os supervisores possam avaliar a solidez dos bancos, valorizando as práticas através do processo de revisão da supervisão estabelecido no Pilar 2 no âmbito do quadro de Basiléia II". O mesmo documento ainda chama a atenção para o Princípio 9, BIS (2009, p.11): "Os supervisores podem exigir dos bancos que forneçam informações complementares para auxiliá-los nos processos de avaliação e de controle”.

Estas preocupações relacionadas ao controle de riscos e à sustentabilidade no longo prazo das instituições financeiras são atuais e relevantes e necessitam de mudanças relacionadas à avaliação e controle de riscos.

$\mathrm{Na}$ avaliação de risco (rating), [deve-se] observar a necessidade de uma revisão independente da governança interna e do modelo, além de promover transparência em uma série de fatores de risco em produtos estruturados e, ao mesmo tempo, incentivar investidores à maior responsabilidade na avaliação dos investimentos. Há ainda esforço para desenvolver princípios nos quais se alinham performance de longo prazo aos interesses dos acionistas. $\mathrm{O}$ objetivo dessas propostas é fortalecer a transparência e a divulgação de produtos. A adoção dessas medidas, as quais devem ser discutidas minuciosamente pela indústria assim que tornadas públicas, pode ajudar a prever os distúrbios recentes que tivemos (RESENHA BMF- Nr. 176-Abril/2009 (2009, p.53)).

Diante do exposto, esta pesquisa foi desenvolvida com o objetivo de analisar a sustentabilidade financeira das cooperativas de crédito brasileiras, neste contexto de necessidade de estabelecer instrumentos de avaliação para auxiliar no controle e previsão de problemas que possam colocar em risco importantes instituições responsáveis pelo fornecimento de crédito ao setor produtivo nacional.

Um dos propósitos é analisar de forma detalhada um dos três pilares, o econômico/financeiro do desenvolvimento sustentável, que, de acordo com o Relatório Brundtland (1987), é definido como "desenvolvimento que satisfaz as necessidades presentes sem comprometer a capacidade das gerações futuras de satisfazer suas próprias necessidades". 


\section{A importância do crédito e do microcrédito no desenvolvimento econômico}

O crédito tem demonstrado ser, na maioria dos países, um instrumento que alavanca o desenvolvimento. Os países com desenvolvimento financeiro intermediário ou avançado, como demonstra o Quadro 1, em uma amostra de 37 países, apresentam relação crédito total/PIB elevados.

Quadro 1. Médias de crédito privado/PIB por estágio de desenvolvimento financeiro

\begin{tabular}{|l|l|l|c|c|c|}
\hline \multicolumn{2}{|l|}{ Desenvolvimento Financeiro } & $\begin{array}{c}\text { Crédito } \\
\text { Bancário/PIB }\end{array}$ & $\begin{array}{c}\text { Crédito Não- } \\
\text { Bancário/PIB }\end{array}$ & $\begin{array}{c}\text { Crédito } \\
\text { Total/PIB }\end{array}$ \\
\hline G1 & 12 países & Incipiente & $23,80 \%$ & $1,80 \%$ & $25,60 \%$ \\
\hline G2 & 19 países & Intermediário & $100,10 \%$ & $-0,20 \%$ & $99,90 \%$ \\
\hline G3 & 6 países & Avançado & $71,50 \%$ & $52,50 \%$ & $124,00 \%$ \\
\hline \multicolumn{2}{|l|}{ Total (37 países) } & & $\mathbf{7 0 , 8 0 \%}$ & $\mathbf{9 , 0 0 \%}$ & $\mathbf{7 9 , 7 0 \%}$ \\
\hline
\end{tabular}

Fonte: Desenvolvimento Financeiro e o Mecanismo de Transmissão da Política Monetária. PUC-Rio - Certificação Digital Nr. 0512362/CB. (www2.dbd.puc-rio.br/pergamum/ tesesabertas/0512362_07_cap_03.pdf). Acesso em 15/03/2008.

O grupo de países com desenvolvimento financeiro incipiente tem baixa relação crédito/PIB, principalmente o não bancário. O crédito total/PIB é de $25,6 \%$. No outro extremo, os países de desenvolvimento avançado têm alta realção crédito/PIB, chegando a $124 \%$. A tabela evidencia a relação positiva entre desenvolvimento e crédito.

Apesar do aumento dos últimos anos, a oferta de crédito no Brasil é uma condição necessária para que a economia tenha desenvolvimento maior. Para o desenvolvimento da economia, é necessário fazer fluir os recursos que sobram de agentes econômicos que não pretendem investir para aqueles que têm projetos viáveis e que vislumbram oportunidades e não têm recursos financeiros suficientes.

O sistema financeiro no Brasil está concentrado em poucos grandes bancos com centenas ou milhares de agências espalhadas pelo País, quando tomadas suas participações em volumes de depósitos ou empréstimos. Todavia, a quantidade de instituições que atuam na ponta do varejo, ofertando produtos e serviços aos pequenos tomadores é relevante, e, nesse sentido, destacam-se as cooperativas de crédito e similares, com sua atuação em microfinanças. 
640 - Sustentabilidade Financeira das Instituições de Microfinanças Brasileiras: Análise das Cooperativas de Crédito Singulares

Nas definições de Nichter, Goldmark \& Fiori (2002, p. 15) "microfinanças são a prestação de serviços financeiros, stricto sensu (bancos, financeiras, SCMs, e cooperativas) ou não (ONGs e Oscips), para indivíduos e empresas excluídas do sistema financeiro tradicional". Quanto ao microcrédito, o definem como "a concessão de empréstimos de relativamente pequeno valor, para atividade produtiva, no contexto de microfinanças".

O microcrédito assumiu a posição de condição necessária ao desenvolvimento de pequenos empreendimentos empresariais ou familiares, capaz de melhorar a condição de renda de classes menos favorecidas, tanto no Brasil como em vários países com menor nível de bancarização.

Neste contexto, o BNDES (Banco Nacional de Desenvolvimento Econômico e Social), através do Programa de Desenvolvimento Institucional (PDI), em convênio de cooperação técnica com o BID (Banco Interamericano de Desenvolvimento), criou mecanismos institucionais de desenvolvimento do microcrédito no Brasil.

O objetivo do PDI é fortalecer a indústria das microfinanças no Brasil. A visão de futuro é de um mercado que oferte, de forma sustentável, serviços financeiros aos microempreendedores, formais ou informais, e a segmentos da população que não lhes têm acesso, ou o têm de maneira restrita. Espera-se que as instituições de microfinanças sejam capazes de oferecer uma gama de produtos adequada às necessidades do seu público-alvo, e que se integrem cada vez mais ao sistema financeiro formal (BRUSKY \& FORTUNA (2002, p. 3)).

As microfinanças têm sido motivo de estudos e preocupação em vários países, pelo seu potencial de geração de renda e desenvolvimento por meio do trabalho, principalmente dos mais necessitados. Conforme mostra Barry (2005), "os clientes de microfinanças querem mais, mais rápido e melhor: rapidez do valor e conveniência; querem acesso a empréstimos maiores; querem respeito e reconhecimento; importam-se com as taxas de juros". A autora chama a atenção para o fato de que os clientes de microfinanças buscam empréstimos empresariais e imobiliários, têm necessidades de curto, médio e longo prazos.

Santos \& Carrion (2008, p. 1), ao analisar a concessão de microcrédito, propõem uma reflexão sobre como pobreza e microcrédito têm dialogado entre 


\section{Edison Luiz Leismann \& $\cdot \mathbf{6 4 1}$ Charles Ulises de Montreuil Carmona}

si. Afirmam que "entende-se que prevalece o ideário do mainstream das Ciências Econômicas subjacente às iniciativas de microcrédito para os pobres na medida em que esta forma de encarar a questão da pobreza acaba por considerar ainda, e apenas, a pobreza absoluta — o que não inova em termos de como enxergar o problema - , (...). No que se refere à abrangência do microcrédito junto às demais formas de pobreza (carência de capital social e carência de empoderamento), algumas dúvidas ficam sem resposta".

Beck \& Ogden (2007, p.13) apresentam três sugestões para as empresas que forem atuar com apoio ao microcrédito como atividade de responsabilidade social empresarial para evitar serem criticadas de "maquiagem social" (alardear programas de benefício baixo ou nulo): como evitar um resultado indesejável? Primeiro, exija indicadores de sucesso bem definidos - como aumento da renda, qualidade da moradia, matrícula escolar e alimentação - de programas de microcrédito amparados pela empresa e esteja disposto a pagar por esses indicadores. Segundo, tome medidas para aumentar a eficácia do empréstimo: dando orientação vocacional e financeira a tomadores, melhorando o acesso à tecnologia para reduzir o custo da contratação do empréstimo (grifo nosso) ou fazendo pressão por mudanças regulamentares que facilitem a abertura e a expansão de negócios. Terceiro, busque oportunidades para fomentar o crescimento de empresas de pequeno e médio porte em regiões carentes.

Evidentemente, o microcrédito não deve ser visto como o único remédio para resolver o problema da pobreza, que é tida como um problema multidimensional e como tal deve ser resolvido. Porém, tem sido um dos mecanismos encontrados para possibilitar aumentos de renda em atividades produtivas cujos rendimentos marginais são altos e em que o acesso ao crédito pode melhorar as condições de vida dos indivíduos e suas famílias.

Isso remete à importância da avaliação do impacto da presença de Instituições de Microfinanças (IMFs) nas comunidades. Nesse sentido, Silva Junior et al. (2008, p. 13), ao avaliar os impactos do Banco Palmas para o desenvolvimento do território no período 1998/2007, afirmam que "a organização contribuiu não apenas para aumentar o consumo e a circulação de riquezas no bairro, mas elevou a autoestima dos moradores".

Isso demonstra que a atuação das IMFs não pode ficar restrita à oferta de microcrédito, sendo, na visão da comunidade, necessário apoiar outros projetos voltados para o desenvolvimento local.

Sela et al. (2006, p.9-13) mostram a importância do microcrédito a partir da experiência do Banco do Povo de Maringá (PR). Um aspecto interessante 
642 - Sustentabilidade Financeira das Instituições de Microfinanças Brasileiras: Análise das Cooperativas de Crédito Singulares

destacado pelos autores é que, em torno de $2 / 3$ dos tomadores de crédito são mulheres e a aplicação se dá tipicamente em atividades informais. No caso dos homens, de forma geral, a aplicação se dá em atividades formais. Também destacam os autores que "os dados mostram que 66,66\% das pessoas estão na atividade há mais de dois anos, e que, destes, 53,33\% estão há mais de quatro anos no negócio. Ou seja, predominam empréstimos para pessoas que estão há algum tempo na atividade". Sela et al. (2006, p. 15) concluem que "a pesquisa constatou que a condição de vida dos tomadores de microcrédito, na grande maioria, melhorou." Monzoni Neto \& Figueiredo (2008, p.1), ao avaliarem o microcrédito produtivo orientado na renda dos microempreendedores, afirmam que "os resultados indicam que o microcrédito produtivo orientado gera lucro líquido para os microempreendedores e renda disponível para suas famílias". Os autores ainda verificaram que as receitas de vendas dos microempreendimentos dobram após dois anos de programa.

Esses resultados estão de acordo com pesquisas internacionais, que afirmam que a produtividade marginal dos pequenos empreendimentos é alta, o que torna possível a esses pagarem taxas de juros altas o suficiente para a sustentabilidade das IMFs. Christen et al. (1995) apresentam um método de cálculo da autossuficiência para IMFs. Por este método, que relaciona as receitas com as despesas administrativas e financeiras, provisões para devedores duvidosos e doações, se o indicador for igual ou superior a um, a IMF alcançou o ponto de equilíbrio para a autossuficiência, denominado pelo autor de Breakeven Self Sufficiency. Esses mesmos fatores são destacados por Rosenberg (2002) que, procurando definir os aspectos essenciais para que uma instituição de microcrédito seja sustentável em longo prazo, chama a atenção para os componentes a serem acompanhados para definir a taxa de juros a ser cobrada nos empréstimos. Esses fatores são: custos administrativos, perdas dos empréstimos, custos dos fundos, taxa de capitalização desejada e renda dos investimentos.

De acordo com Helms \& Reille (2004, p. 2), três tipos de custos precisam ser cobertos pelas taxas de juros: o custo de fundos para repasse, o ligado ao risco (inadimplência) e os custos administrativos (identificação e seleção de clientes, processamento de pedidos de empréstimo, desembolso de empréstimos, coleta e acompanhamento dos pagamentos). Por outro lado, Waterfield \& Ramsing (1998, p.58) destacam a questão da produtividade. Segundo os autores, "os indicadores de produtividade geralmente são de maior interesse da gestão do que de reguladores externos. Estes apenas interessam-se pela influência indireta que a produtividade exerce sobre a segurança e a solidez". Ao tratar dos indicadores de produtividade, os dividem em três áreas: produtividade 
operacional (o uso de pessoal de escritório e recursos); produtividade financeira (o uso de recursos financeiros) e o da eficiência. Ressaltam que esses indicadores são todos uma relação de saídas sobre entradas.

Ainda no contexto internacional, Wright, D. \& Alamgir, D. (2004), ao analisarem os determinantes da taxa efetiva e taxas médias em Bangladesh, mostram que o custo médio de captação ficava em torno de $12 \%$ e 15\%; as despesas administrativas, entre $15 \%$ e $25 \%$ da carteira; as perdas com empréstimos, em torno de $2 \%$; a taxa de capitalização da instituição, entre $6 \%$ e 8\%; o que leva à necessidade de uma taxa anual de juros efetiva em torno de $35 \%$ a $50 \%$ para tornar a IMF sustentável financeiramente.

Na outra ponta, entre outros aspectos, como destacado por Olivera (2004), o custo efetivo é um problema para os tomadores de crédito. Conclui que os problemas mais importantes de acesso ao crédito são as taxas de juros, falta de garantias, documentos necessários para poder obter um empréstimo e a capacidade de pagamento das unidades empresariais.

Ao analisar as microfinanças no contexto brasileiro, Nichter, Goldmark \& Fiori (2002, p.16) mostraram que "o Programa de Desenvolvimento Institucional (PDI) estima que o segmento local de microfinanças consiste de 121 instituições atendendo a um total de 158.654 clientes ativos". Todavia, tomando-se como referência que grande parte das operações de crédito das cooperativas de crédito, SCM e crédito mútuo, têm valores em torno de $\mathrm{R} \$ 3$ mil, para fins das análises desenvolvidas neste trabalho, consideram-se os números de 2008, com 1.492 instituições com essas características. O Quadro 2 mostra a distribuição das 1.492 instituições cooperativas e outras ligadas à área de microfinanças em 2008 no Brasil.

As instituições de crédito mútuo representam 61,19\% das instituições, seguidas pelas de crédito rural com 25,34\%. As de livre admissão, com 9,92\%, são, em grande parte, atuantes no meio rural, no financiamento de atividades agrícolas e com forte relacionamento com cooperativas agrícolas. Desta forma, em torno de 1/3 da quantidade existente de cooperativas de crédito tem no desenvolvimento rural sua atuação principal. 
644 - Sustentabilidade Financeira das Instituições de Microfinanças Brasileiras: Análise das Cooperativas de Crédito Singulares

Quadro 2. Distribuição das IMFs (Instituições de Microfinanças) no Brasil (2008)

\begin{tabular}{|c|r|r|}
\hline TIPO DE IMF & Quantidade & Participação \% \\
\hline Crédito Mútuo & 913 & $61,19 \%$ \\
\hline Crédito Rural & 378 & $25,34 \%$ \\
\hline Livre Admissão & 148 & $9,92 \%$ \\
\hline SCM & 43 & $2,88 \%$ \\
\hline Luzzatti & 10 & $0,67 \%$ \\
\hline TOTAL & $\mathbf{1 . 4 9 2}$ & $\mathbf{1 0 0 , 0 0 \%}$ \\
\hline
\end{tabular}

Fonte: Desenvolvido pelos autores com base em dados do Banco Central do Brasil.

Entretanto, destaca-se que, nos últimos anos, têm crescido a participação das cooperativas de crédito de livre admissão, sendo estas também detentoras de grande parte dos ativos totais e empréstimos do setor, mesmo representando em torno de $10 \%$ do total de instituições em atividade, como evidenciado no quadro 2. Esse aspecto é destacado pelo Banco Central do Brasil (2010), informando que o segmento de crédito cooperativo brasileiro conta com mais de três milhões de associados em todo o Brasil, número que se encontra em significativa expansão. O segmento tem se caracterizado, nos últimos anos, por uma trajetória de crescimento e constante mudança em relação ao perfil das cooperativas. Novos tipos de cooperativas de crédito foram introduzidos pela regulamentação, possibilitando a atuação com o público em geral, as cooperativas de livre admissão. Soares \& Melo Sobrinho (2009, p. 79) destacam que isso ocorreu a partir de 2003, quando a resolução 3.106 de 25/06/2003 do Conselho Monetário Nacional permitiu a abertura do quadro social.

\section{Administração do risco de crédito}

Os passivos dos agentes financeiros referem-se aos recursos que os mesmos captam para emprestar. Normalmente, esses agentes financeiros emprestam recursos captados no mercado, sendo que os recursos próprios representam pequena parte dos valores emprestados. Isso significa que os agentes financeiros trabalham com alta alavancagem financeira.

Os ativos dos bancos podem ser classificados em quatro principais categorias que geram receitas, conforme mostra Saunders (2000, p.27): "empréstimos a pessoas jurídicas (ou empréstimos comerciais e industriais), títulos, empréstimos 
hipotecários e crédito pessoal". No caso de títulos, os títulos públicos dominam esse mercado. No Brasil, no caso dos empréstimos hipotecários, normalmente voltados ao crédito imobiliário, a concentração se dá através do Sistema Financeiro da Habitação, em que a Caixa Econômica Federal absorve grande parte da demanda. Os empréstimos a pessoas jurídicas e o crédito pessoal surgem então como o principal item de ativos em que as instituições financeiras, objeto deste estudo, atuam. Saunders (2000, p.28) ressalta que "a exposição a risco de crédito ou inadimplência é um elemento importante de risco para os atuais administradores de bancos comerciais".

Normalmente, quando se fala em risco, tem-se que o mesmo é o elemento central da análise, esquecendo-se de que risco e retorno são dois conceitos que devem andar, obrigatoriamente, juntos. Carmona \& Lucena (2009, p. 75) afirmam que "risco, de certa forma, é associado com a possibilidade de perda. (...) pode ser considerado como a possibilidade de perda financeira, já que tratamos de investimentos em dinheiro".

Trazendo essa questão dos retornos para os empréstimos dos agentes financeiros, Saunders (2000, p. 202) mostra que diversos fatores afetam o retorno prometido num empréstimo qualquer: "a taxa de juros do empréstimo, quaisquer comissões associadas a um empréstimo, o prêmio por risco de crédito no empréstimo, a garantia associada ao empréstimo e outras condições que não envolvam preço (como saldo mínimo e reservas compulsórias)”.

Ao definirem risco, Bernstein \& Damodaram (2000, p.20) afirmam que "a existência do risco pressupõem que não conhecemos o que irá acontecer, embora ocasionalmente tenhamos uma boa idéia do leque de possibilidades que devemos enfrentar".

Caouette, Altman e Narayanam (1998) observam que os administradores financeiros não se preocuparam tanto em criar metodologias ou técnicas mais eficazes para previsão da inadimplência, mas sim procuraram desenvolver e consolidar as bases de informação sobre os clientes de forma a torná-las mais confiáveis.

Nesse sentido, o Banco Central do Brasil também desenvolve estudos, como o de Soares \& Melo Sobrinho (2007, p.143), em que afirmam que: 
646 - Sustentabilidade Financeira das Instituições de Microfinanças Brasileiras: Análise das Cooperativas de Crédito Singulares

sob a ótica da supervisão e da regulamentação, o desafio maior é, portanto, estimular, consolidar e fortalecer as iniciativas que atuam na oferta de serviços financeiros para aquelas populações, com expectativa de que essas iniciativas possam ser não apenas autossustentáveis, mas também capazes de despertar o interesse de investidores privados.

Nas IMFs, a concessão de microcrédito é fator chave do sucesso ou insucesso das mesmas. Neste sentido, cabe ao agente de crédito, que visita os possíveis tomadores de crédito e avalia suas condições de pagamentos, tomar a decisão de concessão ou não e os montantes adequados. Assim sendo, surge uma questão importante: a ética do agente de crédito nesse processo de avaliação e concessão de crédito. Moura et al. (2008, p.1) realizaram pesquisa com 48 agentes de microcrédito da Unibanco Microinvest dos estados de Rio de Janeiro, São Paulo, Rio Grande do Sul, Espírito Santo e Minas Gerais. Este grupo representa a totalidade dos agentes de microcrédito da Instituição, permitindo assim resultados mais acurados na população estudada. Os resultados mostraram que características socioculturais e a formação intelectual dos agentes influenciam sua tomada de decisão - são características que podem levá-los a agir de maneira não ética.

Nesta mesma linha da importância dos agentes de crédito, pesquisa realizada por Araújo \& Carmona (2007, p.123), ao analisar a eficiência dos agentes de crédito na Créd Cidadania em Recife (PE), encontraram diferenças nos resultados da inadimplência em função dos agentes envolvidos, evidenciando a importância da experiência e capacitação profissional nesta área.

Conforme apresentado, a oferta de crédito e de microcrédito é importante no desenvolvimento econômico e social, urbano e rural, sendo ideal que as instituições relacionadas ao setor mantenham-se em atividade e que eventuais problemas possam ser antecipados pelos órgãos reguladores. Destaca-se que, no caso das cooperativas singulares, essa preocupação deve ser também das centrais dessas cooperativas, devido ao fato de estas serem corresponsáveis pelas unidades singulares.

Amorin Neto \& Carmona (2004) apresentam análise da modelagem do risco de crédito no segmento de pessoas físicas em banco de varejo a partir dos modelos multivariados. Os resultados mostram "similaridade da eficiência de análise discriminante e regressão logística”.

Também Padelo Junior (2006, p.11) aplicou a análise discriminante para 
previsão de insolvência bancária e afirma que a construção de um modelo baseado em dados contábeis, e, portanto, disponíveis para a população em geral, seria uma maneira de se reduzir o risco de uma crise bancária mais acentuada, pois a um só tempo permitiria uma ação mais tempestiva e eficaz por parte do Banco Central e uma melhor identificação e mensuração do risco existente nas instituições financeiras, por parte do público em geral.

Nesta pesquisa, avalia-se a aplicação da Análise Discriminante no contexto dos demonstrativos financeiros sintéticos divulgados pelo Banco Central do Brasil, incorporando algumas variáveis macroeconômicas dos estados a que pertencem as instituições analisadas.

\section{Metodologia}

\subsection{População e amostra}

O Banco Central do Brasil disponibiliza dados sobre o Sistema Financeiro Nacional. Os dados das instituições financeiras são apresentados a partir de informações contábeis sintéticas, o que permite as análises propostas nesta pesquisa. Para tanto, foram selecionados os valores dos balanços de 31/12/ 2007. Estes dados do Banco Central de todas as instituições, portanto também das pequenas cooperativas, que são foco do interesse desta pesquisa, são das seguintes contas: das contas do ativo, são apresentados os valores agregados correspondentes aos estabelecidos pelo Cofif (Plano Contábil das Instituições Financeiras Nacionais), que são: Cosif - CONTAS ATIVO (1.0.0.00.007+2.0.0.00.00-4) e do PASSIVO (6.0.0.00.00-2); e RESULTADOS (7.0.0.00.00$9+8 \cdot 0 \cdot 0 \cdot 00 \cdot 00-6)$.

Dos dados disponibilizados, foram selecionados os valores das cooperativas singulares de 2007. Também foram obtidos os balanços das 31 instituições que foram liquidadas entre 2003 e 2006. Estatísticas do Banco Central de 2008 mostram que são 1.492 Instituições Financeiras do tipo cooperativas de crédito, Sociedades de Crédito ao Microempreendedor ( $\mathrm{SCM}$ ) e de crédito mútuo atualmente no Brasil. A classificação e análises desta pesquisa ocorrem com os dados dessas instituições. Todavia, trabalhou-se com valores de 31/12/2007 e somente com as cooperativas singulares, sendo 1.439, e mais 31 liquidadas, estas com os valores do ano anterior à liquidação, totalizando 1.470.

O banco de dados foi dividido aleatoriamente em duas partes, cada qual com 735 instituições, sendo a primeira composto por 720 "em atividade" e 15 
648 - Sustentabilidade Financeira das Instituições de Microfinanças Brasileiras: Análise das Cooperativas de Crédito Singulares

"liquidadas", denominada de amostra de desenvolvimento e a segunda, composta por 719 "em atividade" e 16 "liquidadas", denominada de amostra de validação. Utilizando-se da técnica Análise Discriminante, analisou-se a eficácia do modelo de previsão de classificação para estimar em qual grupo novas instituições analisadas podem pertencer.

Uma segunda análise foi realizada com a separação do banco de dados em quatro grupos com 367 instituições cada uma, tendo como critério o tamanho, medido pelo valor do ativo. O primeiro grupo, denominado de Micros, engloba instituições com ativos totais até $\mathrm{R} \$ 1.171 .163,66$, no limite do primeiro quartil (0 a $25 \%$ da população). O segundo, denominado de Pequenas, tem valores superiores ao limite anterior até o valor de $\mathrm{R} \$ 4.364 .239,17$, no limite do segundo quartil [25\% (exclusive) a $50 \%$ da população]. O terceiro grupo, denominado de Médias, tem valores superiores ao limite anterior até o valor de $\mathrm{R} \$ 14.961 .902,28$, no limite do terceiro quartil [50\% (exclusive) a 75\% da população]. O último grupo foi denominado de Grandes e tem valores entre R \$ 15.157.948,12 e $\mathrm{R} \$ 1.225 .924 .197,59$, entre $75 \%$ (exclusive) e $100 \%$ da população. Nestas análises, optou-se pelo procedimento de cross-validation, em que se cria uma variável aleatória, que será utilizada pelo software SPSS ${ }^{\circledR}$ no desenvolvimento da função discriminante e deste teste.

\subsection{Indicadores utilizados na análise dos dados}

Com relação aos dados das cooperativas singulares e similares, foram utilizados 17 indicadores para análise, conforme mostra o quadro 3. Os dados foram padronizados a partir da equação 01.

Valor Padronizado $=($ Valor Variável Calculada - Valor Mín. $) /($ Valor Máx. - Valor Mín) (01)

Destaca-se que são 14 indicadores oriundos dos dados disponibilizados pelo Banco Central do Brasil e três indicadores macroeconômicos dos anos 2000 e 2006, obtidos junto ao banco de dados do Ipea (2008). Para algumas análises, os valores das variáveis foram padronizados a partir da equação 01 (valores mínimos e máximos referem-se às variáveis explicativas da amostra) e o quadro 3 mostra o nome e a descrição dessas variáveis, utilizados nos modelos de análise. Muitas são obtidas diretamente dos dados, outras a partir das equações apresentadas a seguir. As equações 02 a 15 podem ser encontradas em Carmona \& Lucena (2009, p.34-41) e em Brealey \& Myers (2005, p.363-367).

A variável interna 6 "Patrimônio de Referência" = PR, é obtida a partir da equação 02 . 
A equação 03 mostra o retorno sobre o patrimônio líquido (RSPL), variável interna 8.

RSPL $=$ Sobras Líquidas / Patrimônio Líquido

Quadro 3. Nome e definição das variáveis

\begin{tabular}{|l|l|l|}
\hline VARIÁVEL & SIGLA & DESCRIÇÃO \\
\hline Interna 1 & ACRLP & Ativo Circulante + Realizável no Longo Prazo \\
\hline Interna 2 & AP & Ativo Permanente \\
\hline Interna 3 & ATIVOTOTAL & Ativo Total \\
\hline Interna 4 & PCELP & Passivo Circulante + Exigível no Longo Prazo \\
\hline Interna 5 & PL & Patrimônio Líquido \\
\hline Interna 6 & PR & Patrimônio de Referência \\
\hline Interna 7 & SOBRAS & Sobras do Ano \\
\hline Interna 8 & RSPL & Retorno Sobre o Patrimônio Líquido \\
\hline Interna 9 & RSA & Retorno Sobre o Ativo \\
\hline Interna 10 & DC & Relação Dívida/Capitalização \\
\hline Interna 11 & PERMPL & Relação Ativo Permanente/Patrimônio Líquido \\
\hline Interna 12 & PLAP & Relação Patrimônio Líquido/Ativo Permanente \\
\hline Interna 13 & PLAT & Independência Financeira \\
\hline Interna 14 & RCREDRDEV & Ratio do Somatório das Contas Credoras/Devedoras \\
\hline Definição & RESULCRE & Somatório das Contas Credoras do Ano \\
\hline Definição & RESULDEB & Somatório das Contas Devedoras do Ano \\
\hline Macro 1 & IDH2000 & Índice de Desenvolvimento Humano da UF em 2000. \\
\hline Macro 2 & APLIC & Total de Aplicações Financeiras na UF em 2006. \\
\hline Macro 3 & PIBpc & PIB Per Capita na UF em 2006 \\
\hline
\end{tabular}

Fonte: Resultados da pesquisa.

A variável interna 9 é calculada a partir da equação 04 e representa uma medida de retornos líquidos do período sobre os ativos totais $(\mathrm{RSA}=$ Retorno sobre o Ativo).

RSA $=$ Sobras $/$ Ativo Total

A variável interna 10 demonstra a relação entre o total de dívidas e o ativo total (DC), demonstrando quanto do ativo total é financiado com recursos 
650 - Sustentabilidade Financeira das Instituições de Microfinanças Brasileiras: Análise das Cooperativas de Crédito Singulares

de terceiros (equação 05).

DC = Passivo Exigível / Ativo Total

A variável interna 11 é calculada a partir da equação 06 e mostra o grau de imobilização do patrimônio líquido. Os ativos permanentes são necessários, porém não podem consumir a maior parte dos recursos próprios. Esse indicador demonstra quanto dos recursos próprios são consumidos pelo ativo permanente.

PERMPL =Ativo Permanente $/$ Patrimônio Líquido

A equação 06 demonstra quanto o ativo permanente consome do capital próprio, sendo um indicador que deve ser minimizado. Ao utilizar o inverso, temos o número de vezes que o patrimônio líquido supera o ativo permanente, sendo um indicador que, quanto maior, mais sustentável financeiramente é a instituição.

A equação 07 demonstra esse indicador referente à variável interna 12.

PLAP = Patrimônio Líquido / Ativo Permanente

A equação 08 mostra a independência financeira, ou seja, quanto do ativo total é financiado com recursos próprios, variável interna 13.

PLAT = Patrimônio Líquido / Ativo Total

O cálculo da autossustentabilidade encontrado na literatura relaciona o total de entradas com as saídas (contas de resultados credoras em relação às contas de resultados devedoras), denominada de Ratio entre Contas Credoras e Contas Devedoras (em módulo). Para avaliar este aspecto, a sigla do indicador foi denominada RCREDRDEV, sendo que são consideradas sustentáveis, no período, quando o indicador for superior a 1. Isso equivale a dizer que as sobras devem ser positivas. A equação 09 mostra esse indicador referente à variável interna 14 . 
RCREDRDEV = Contas de Resultados Credoras /

Contas de Resultados Devedoras

As outras variáveis foram obtidas diretamente dos bancos de dados consultados.

\subsection{Análise Discriminante}

Na Análise Discriminante, conforme nos mostra Mingoti (2005, p.213256), "é necessário que os grupos para os quais cada elemento amostral pode ser classificado sejam predefinidos, ou seja, conhecidos a priori considerandose suas características gerais". Este é o caso do presente banco de dados em que a população é separada em "liquidadas" (0) e "em atividade" (1). Na primeira análise (Resultados 5.1), o banco de dados foi dividido aleatoriamente em duas partes, cada qual com 735 instituições, sendo a primeira composta por 720 "em atividade" e 15 "liquidadas", denominada de amostra de desenvolvimento e a segunda, composto por 719 "em atividade" e 16 "liquidadas", denominada de amostra de validação.

Conforme apresentado por Mingoti (2005, p. 216), as equações 10, 11 e 12 evidenciam o cálculo da classificação para duas populações.

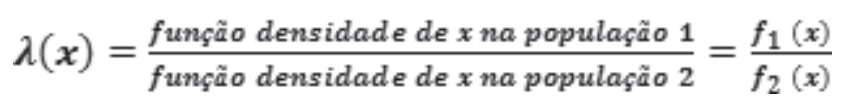

Na equação 10, o lambda de x [ $\lambda(x)]$ é calculado como uma relação entre as funções densidade de probabilidade das duas populações. Admitindo-se normalidade multivariada, lineraridade, ausência de outliers, ausência de multicolinearidade e homogeneidade das matrizes de variância-co-variância, essa classificação pode ser realizada. A equação 11 demonstra o cálculo de forma mais específica, em que "x" refere-se aos valores das variáveis, $\mu_{1}$ e $\mu_{2}$ são as médias e $\sigma$ é o desvio padrão das variáveis. Sendo que exp demonstra a

função matemática exponencial: $\lambda(\boldsymbol{x})=\frac{\frac{1}{\sqrt{2 \pi \sigma}} \exp \left\{\frac{-1}{2}\left(\frac{x-\mu_{1}}{\sigma}\right)^{2}\right\}}{\frac{1}{\sqrt{2 \pi \sigma}} \exp \left\{\frac{-1}{2}\left(\frac{x-\mu_{2}}{\sigma}\right)^{2}\right\}}$ 
652 - Sustentabilidade Financeira das Instituições de Microfinanças Brasileiras: Análise das Cooperativas de Crédito Singulares

Que pode ser reduzida, conforme a equação 12:

$$
\lambda(x)=\exp \left\{\frac{-1}{2}\left[\left(\frac{x-\mu_{1}}{\sigma}\right)^{2}-\left(\frac{x-\mu_{2}}{\sigma}\right)^{2}\right]\right\}
$$

Os resultados foram obtidos a partir do método Stepwise e foram submetidos a testes estatísticos para verificação das hipóteses acima definidas, conforme detalhado no item "resultados". Os testes foram analisados conforme Corrar et al. (2007, p.252-264). O "Z” crítico ou Ponto de Corte é calculado após a obtenção dos valores "centroids" dos grupos discriminantes $1\left(C_{1}\right)$ e $2\left(C_{2}\right)$, divididos pela soma do número de observações em cada grupo $\left(N_{1}+N_{2}\right)$, a partir da equação 13.

$Z_{\text {crítico }}=\frac{N_{2} C_{1}+N_{1} C_{2}}{N_{1}+N_{2}}$

\section{Resultados}

\subsection{Modelo 1: Análise Discriminante para valores sem padronização}

Numa primeira tentativa de análise com o método stepwise, estimou-se o modelo discriminante sobre os dados em seus valores originais da amostra de desenvolvimento e realizou-se o teste no banco de dados da amostra de validação, cada qual com 735 instituições. Esta tentativa teve por objetivo evidenciar uma função discriminante que pudesse ser aplicada sobre os dados originais, sem transformações, o que facilita a utilização pelos que poderão utilizar o instrumento de análise.

Conforme mostra o quadro 4 (Box's M), com nível de significância 0,000 (Sig.), existe evidência estatística para rejeitar a hipótese nula de homogeneidade das matrizes de variância-co-variância, atendendo a este requisito da análise. 
Edison Luiz Leismann \& $\cdot \mathbf{6 5 3}$

Charles Ulises de Montreuil Carmona

Quadro 4. Teste de igualdade das matrizes de variância-co-variância

\begin{tabular}{|c|c|}
\hline Box's M & $12.923,485$ \\
\hline $\begin{array}{ll}\mathrm{F} & \text { Approx. }\end{array}$ & 373.988 \\
\hline Df1 & 28 \\
\hline$\overline{\mathrm{Df2}}$ & 1.991 .714 \\
\hline Sig & 0 \\
\hline
\end{tabular}

Fonte: Resultados da pesquisa.

Os modelos do quadro 5 apresentam nível de significância 0,000 pelo teste Wilk's Lambda, o que mostra que os modelos conseguem separar e classificar bem os grupos.

Observa-se, no quadro 5, que as Sobras (equivalentes ao lucro líquido do exercício) são o fator com maior poder de explicação para separar as empresas "liquidadas" e "em atividade".

Na sequência, são incorporados aos modelos o Patrimônio Líquido (PL), Retorno sobre ativos (RSA), Retorno sobre o Patrimônio Líquido (RSPL), Somatório do Ativo Circulante com o Realizável a Longo Prazo (ACRLP), Ativo Permanente (AP) e, por último, no modelo 7, a Relação Patrimônio Líquido sobre o Ativo Permanente (PLAP). 
654 - Sustentabilidade Financeira das Instituições de Microfinanças Brasileiras: Análise das Cooperativas de Crédito Singulares

Quadro 5. Modelos selecionados pelo Método Stepwise

\begin{tabular}{|c|c|c|c|c|}
\hline 1 & SOBRAS & 1,000 & 0,000 & \\
\hline \multirow[b]{2}{*}{2} & SOBRAS & 0,220 & 0,000 & 0,996 \\
\hline & $\mathrm{PL}$ & 0,220 & 0,000 & 0,711 \\
\hline \multirow[b]{3}{*}{3} & SOBRAS & 0,220 & 0,000 & 0,903 \\
\hline & PL & 0,220 & 0,000 & 0,660 \\
\hline & RSA & 0,999 & 0,000 & 0,392 \\
\hline \multirow[b]{4}{*}{4} & SOBRAS & 0,220 & 0,000 & 0,833 \\
\hline & $\mathrm{PL}$ & 0,220 & 0,000 & 0,621 \\
\hline & RSA & 0,392 & 0,000 & 0,391 \\
\hline & RSPL & 0,392 & 0,000 & 0,374 \\
\hline \multirow[b]{5}{*}{5} & SOBRAS & 0,212 & 0,000 & 0,833 \\
\hline & $\mathrm{PL}$ & 0,130 & 0,000 & 0,421 \\
\hline & RSA & 0,392 & 0,000 & 0,383 \\
\hline & RSPL & 0,392 & 0,000 & 0,366 \\
\hline & ACRLP & 0,180 & 0,000 & 0,360 \\
\hline \multirow[b]{6}{*}{6} & SOBRAS & 0,210 & 0,000 & 0,833 \\
\hline & $\mathrm{PL}$ & 0,129 & 0,000 & 0,420 \\
\hline & RSA & 0,392 & 0,000 & 0,379 \\
\hline & RSPL & 0,392 & 0,000 & 0,362 \\
\hline & ACRLP & 0,098 & 0,000 & 0,360 \\
\hline & $\mathrm{AP}$ & 0,166 & 0,008 & 0,353 \\
\hline \multirow[b]{7}{*}{7} & SOBRAS & 0,208 & 0,000 & 0,831 \\
\hline & $\mathrm{PL}$ & 0,124 & 0,000 & 0,420 \\
\hline & RSA & 0,391 & 0,000 & 0,376 \\
\hline & RSPL & 0,392 & 0,000 & 0,359 \\
\hline & ACRLP & 0,098 & 0,000 & 0,356 \\
\hline & AP & 0,165 & 0,005 & 0,351 \\
\hline & PLAP & 0,952 & 0,017 & 0,350 \\
\hline
\end{tabular}

Fonte: Resultados da pesquisa.

Os resultados dos testes mostraram que a Correlação Canônica (quadro 6) obteve o valor de 0,808, o que representa um poder de explicação de 65,29\% (obtido pelo quadrado deste valor $=0,808^{2}=0,6529$ ), do modelo da função discriminante 7 (quadro 5), selecionado pelo método stepwise e apresentado na quadro 8.

Quadro 6. Correlação Canônica

\begin{tabular}{|l|l|l|l|l|}
\hline Função & Eigenvalue & $\%$ de Variância & $\%$ Cumulativo & Correlação Canônica \\
\hline 1 & $1,884 a$ & 100,0 & 100,0 & 0,808 \\
\hline
\end{tabular}
a= First 1 Canonical discrimant functions were used in the analysis.

Fonte: Resultados da pesquisa.

O teste Wilk's Lambda do modelo selecionado mostra significância de 0,000, demonstrando que o modelo consegue separar e classificar bem os grupos. 
Quadro 7. Teste Wilks' Lambda

\begin{tabular}{|c|r|r|r|r|}
\hline Teste da Função & Wilks'Lambda & Chi-square & df & \multicolumn{1}{|l|}{ Sig. } \\
\hline 1 & 0,347 & 772.564 & 7 & 0,000 \\
\hline
\end{tabular}

Fonte: Resultados da pesquisa.

A função discriminante canônica obtida pelo método stepwise no banco de dados da amostra de desenvolvimento selecionou sete variáveis (quadro 8). Observa-se que os sinais negativos das variáveis PL (Patrimônio Líquido) e RSPL (Retorno sobre o Patrimônio Líquido), contradizem a teoria, pois deveriam apresentar sinais positivos.

Quadro 8. Função Discriminante Canônica

\begin{tabular}{|l|r|}
\hline \multicolumn{2}{|l|}{ Coeficientes da Função Discriminante Canônica } \\
\hline ACRLP & 0,000000009439417441 \\
\hline AP & 0,000000131692116948 \\
\hline PL & 0,000000093080071431 \\
\hline SOBRAS & 0,000001617327146872 \\
\hline RSPL & 0,014867914281412700 \\
\hline RSA & 0,029640036309267400 \\
\hline PLAP & 0,111511613930116000 \\
\hline (Constant) & 0,278741662308333000 \\
\hline Unstandardized coefficients \\
\hline
\end{tabular}

Fonte: Resultados da pesquisa.

As funções centroids calculadas foram -9,496 para as "liquidadas" e 0,198 para as "em atividade". Aplicando-se a equação para definir o ponto de corte, obtém-se -9,2982:

$$
Z_{\text {crítico }}=\frac{N_{2} C_{1}+N_{1} C_{2}}{N_{1}+N_{2}}=\frac{(720 x-9,496)+(15 x 0,198)}{720+15}=-9,2982
$$

Os resultados mostram a efetividade da discriminação, sendo que as 15 instituições "liquidadas" do banco de dados de desenvolvimento foram classificadas corretamente, com acerto de 100\%, enquanto o percentual de 
656 - Sustentabilidade Financeira das Instituições de Microfinanças Brasileiras: Análise das Cooperativas de Crédito Singulares

acerto das "em atividade" foi de 99,3\%, classificando somente cinco das 720 como sendo "liquidadas", de forma incorreta (quadro 9).

Quadro 9. Classificação e previsão a partir do banco de dados sem padronização

\begin{tabular}{|cc|c|c|c|}
\hline \multicolumn{5}{|c|}{ Classification Results ${ }^{*}$ a } \\
\hline \multirow{2}{*}{ L0A1 } & Predicted Group Membership & Total \\
\cline { 2 - 5 } & LIQUIDADAS & EM ATIVIDADE & \\
\hline Original Count & LIQUIDADAS & 15 & 0 & 15 \\
\hline & 5 & 715 & 720 \\
\hline$\%$ & LIQUIDADAS & 100,0 & 0,0 & 100,0 \\
\hline$\%$ & EM ATIVIDADE & 0,7 & 99,3 & 100,0 \\
\hline \multicolumn{2}{|c|}{} \\
\hline a: $99,3 \%$ of original grouped cases correctly classified.
\end{tabular}

Fonte: Resultados da pesquisa.

Porém, esses são resultados calculados e aplicados sobre a amostra de desenvolvimento.

Para testar a capacidade do modelo em discriminar os grupos, é necessária a aplicação dos resultados na outra amostra (amostra de validação).

$\mathrm{Na}$ aplicação da função Discriminante no banco de dados da amostra de validação, com 735 instituições, sendo 719 "em atividade" e 16 "liquidadas", obteve-se 56,25\% de acerto na classificação das "liquidadas", ou seja, 9 em 16. No caso das "em atividade", o acerto foi de 717 em 719, ou seja, 99,72\%.

Isso demonstra um potencial maior do modelo calculado com os dados originais na classificação das empresas "em atividade" e um percentual baixo (56,25\%) nas de maior interesse da pesquisa: as "liquidadas". Embora trabalhar com os dados originais facilite o processo para os que atuam na área, a busca de modelos mais aprimorados deve ser feita. Demonstra-se essa forma alternativa no item 5.2.

\subsection{Modelo 2: Análise Discriminante para valores padronizados e separação por quartis}

Diante do que foi apresentado no item anterior, os dados foram separados em quatro grupos, tendo como critério o tamanho das instituições, medido pelo valor do ativo e buscando, com isso, maior homogeneização. Em seguida, foram padronizadas as variáveis explicativas, como mostrado na Equação 1 da Metodologia. 
Os quatro grupos foram separados de acordo com os quartis, com as seguintes classificações: Micros, Pequenas, Médias e Grandes cooperativas, também conforme especificado na Metodologia.

\subsubsection{Modelo 2: Análise Discriminante para valores padronizados para o primeiro quartil - "Micros"}

Apesar dos resultados razoáveis obtidos do item 5.1, segue a classificação Discriminante das microinstituições, com ativos entre $\mathrm{R} \$ 1.053,97$ e $\mathrm{R} \$$ 1.171.163,66, sendo que representam o primeiro quartil (25\%) de todas cooperativas de crédito singulares do Brasil. Os coeficientes da Função Discriminante Canônica para as 367 instituições "Micros", calculados com 256 e testados pelo procedimento cross-validation nas 111 instituições separadas aleatoriamente para o teste, são apresentados na equação 15.

\section{$Z_{\text {Micros }}=-51,927+54,401$ VPADsobras $+3,100 \mathrm{VPADrspl}$}

Observa-se que os sinais positivos das duas variáveis explicativas (Sobras e Retorno sobre o Patrimônio Líquido (RSPL) Padronizados (VPAD)) estão de acordo com a teoria, pois maiores sobras e maiores sobras relativas ao capital próprio atuam favoravelmente para a sustentabilidade financeira das instituições.

A escolha de somente duas variáveis explicativas deve-se ao próprio método stepwise, que seleciona o menor número de variáveis que atendem ao objetivo da classificação. Isso não quer dizer que todas as outras variáveis não atuam no sentido dessa separação de grupos, mas são superadas pelas variáveis selecionadas pelo sistema.

Para definir o ponto de corte, se utilizam os valores dos centróids de cada grupo, aplicando-os na seguinte equação:

$Z_{\text {critico }}=\frac{N_{2} C_{1}+N_{1} C_{2}}{N_{1}+N_{2}}=\frac{(240 x-35,162)+(16 x 2,225)}{240+16}=-32,8253$

Aplicando-se a equação aos valores do banco de dados original das 357 instituições classificadas como Micros e utilizando-se do ponto de corte (Z crítico) de $-32,8253$, os resultados conferem com $100 \%$ de acerto nas instituições "liquidadas" e nas "em atividade", tanto na parte de teste quanto na crossvalidação, com total de 367 em análise, como mostra o quadro 10. 
658 - Sustentabilidade Financeira das Instituições de Microfinanças Brasileiras: Análise das Cooperativas de Crédito Singulares

Aplicando a equação no banco de dados das instituições Médias, ocorreram 99,73\% de acertos nas "em atividade" e acerto na única "liquidada" neste grupo, totalizando 367 instituições. Para as instituições Grandes, ocorreu acerto de 98,64\% nas "em atividade" e também ocorreu acerto na única "liquidada" neste grupo, com total de 368 instituições.

Quadro 10. Dados padronizados das micros - primeiro quartil

\begin{tabular}{|c|c|c|c|}
\hline \multicolumn{4}{|c|}{ Classification Results: b, c, d } \\
\hline \multirow[b]{2}{*}{ Situação de funcionamento } & \multicolumn{2}{|c|}{ Predicted Group Membership } & \multirow[b]{2}{*}{ Total } \\
\hline & LIQUIDADAS & EM ATIVIDADE & \\
\hline Cases Selected Original Count LIQUIDADAS & 16 & 0 & 16 \\
\hline EM ATIVIDADE & 0 & 240 & 240 \\
\hline$\%$ LIQUIDADAS & 100,0 & 0,0 & 100,0 \\
\hline$\%$ EM ATIVIDADE & 0,0 & 100,0 & 100,0 \\
\hline Cross-validated: a Count LIQUIDADAS & 16 & 0 & 16 \\
\hline EM ATIVIDADE & 0 & 240 & 240 \\
\hline$\%$ LIQUIDADAS & 100,0 & 0,0 & 100,0 \\
\hline$\%$ EM ATIVIDADE & 0,0 & 100,0 & 100,0 \\
\hline Cases Not Selected Original Count LIQUIDADAS & 5 & 0 & 5 \\
\hline EM ATIVIDADE & 0 & 106 & 106 \\
\hline$\%$ LIQUIDADAS & 100,0 & 0,0 & 100,0 \\
\hline$\%$ EM ATIVIDADE & 0,0 & 100,0 & 100,0 \\
\hline \multicolumn{4}{|c|}{ a: Cross validation is done only for those cases in the analysis. In cross validation, each case is classified } \\
\hline \multicolumn{4}{|c|}{ by the functions derived from all cases other than that case. } \\
\hline \multicolumn{4}{|c|}{ b: $100,0 \%$ of selected original grouped cases correctly classified. } \\
\hline \multicolumn{4}{|c|}{ c: $100,0 \%$ of unselected original grouped cases correctly classified. } \\
\hline \multicolumn{4}{|c|}{ d: $100,0 \%$ of selected cross-validated grouped casses correctly classified. } \\
\hline
\end{tabular}

Fonte: Resultados da pesquisa.

A Correlação Canônica demonstrada no Quadro 11, elevada ao quadrado $\left[(0,994)^{2}\right]$, nos mostra que 98,8\% da variável dependente ("liquidada" ou "em atividade") pode ser explicada pelo modelo de análise discriminante.

Quadro 11. Estatística Autovalor

\begin{tabular}{|c|c|r|r|c|}
\hline Função & Eigenvalue & $\%$ de Variância & $\%$ Cumulativo & Correlação Canônica \\
\hline 1 & $78,877 a$ & 100,0 & 100,0 & 0,994 \\
\hline
\end{tabular}

Fonte: Resultados da pesquisa.

Pela estatística Wilks' Lambda, quanto mais próximo de zero for esse valor e o nível de significância, mais intensa será a diferença entre os grupos. Como mostra o quadro 12, os valores permitem excelente capacidade de discriminação entre os grupos. 
Quadro 12. Teste Wilks' Lambda

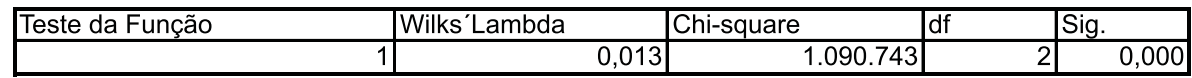

Fonte: Resultados da pesquisa.

Os gráficos 1 e 2 a seguir demonstram os valores das médias e desvios padrão dos dois grupos discriminantes.

\section{Canonical Discriminant Function 1}

\section{Situação de funcionamento $=$ Em Atividade}

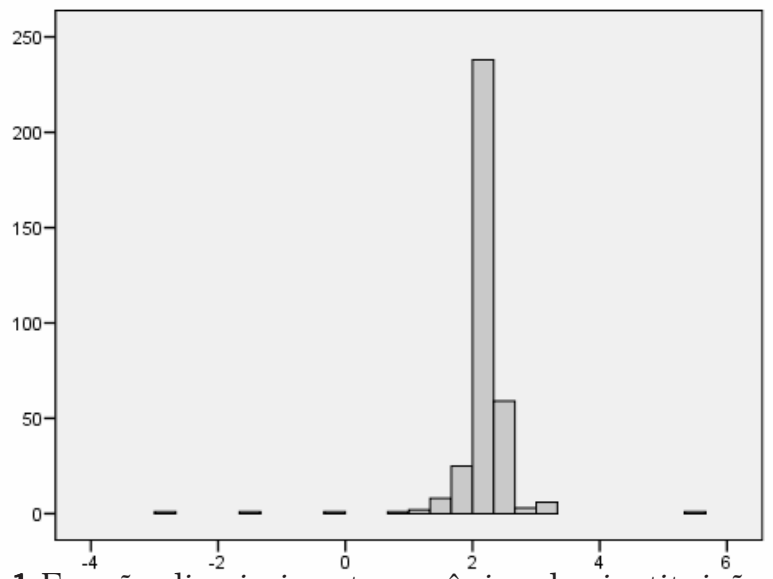

Mean $=2,19$ Std. Dev. $=0,47$

Gráfico 1.Função discriminante canônica das instituições "em atividade" Fonte: Resultados da pesquisa.

O gráfico 1 mostra a média de 2,19 e desvio padrão de 0,47 das instituições "em atividade" (total de 346), e o gráfico 2 mostra a média de -34,62 e o desvio padrão de 3,416 das "liquidadas", que totalizam 21 instituições. 
660 - Sustentabilidade Financeira das Instituições de Microfinanças Brasileiras: Análise das Cooperativas de Crédito Singulares

\section{Canonical Discriminant Function 1}

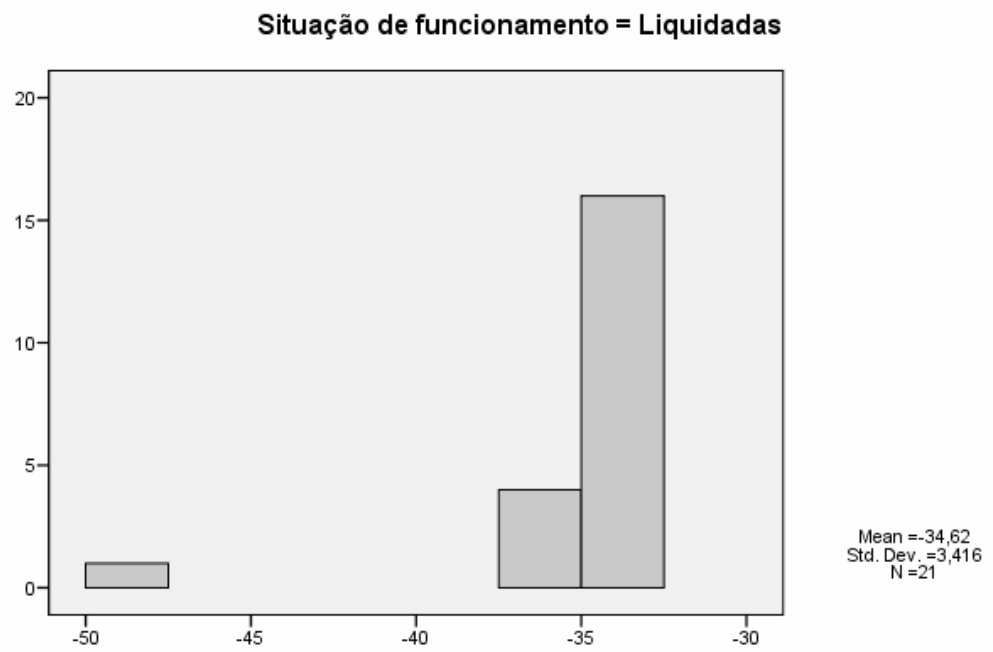

Gráfico 2. Função discriminante canônica das instituições "liquidadas" Fonte: Resultados da pesquisa.

\subsection{Comparações com outras análises realizadas}

\subsubsection{Isif-Créd - Índice de sustentabilidade intrassetorial das cooperativas de crédito}

Este estudo dos autores com a mesma base de dados classificou as instituições em cinco níveis de sustentabilidade financeira, chamados de Índice de Sustentabilidade Financeira Intrassetorial das Cooperativas de Crédito (IsifCréd), numa escala crescente de sustentabilidade (categorias), entre 1 e 5 ( $1=$ Precária; 2= Baixa; 3= Média; 4= Alta; $5=$ Excelente), em que foram considerados os indicadores padronizados, a saber: a-Tamanho (valor do ativo); b-Independência Financeira; c-Imobilização do Patrimônio Líquido; d-Sobras/ Patrimônio Líquido e e-Autossustentabilidade no Período, considerando seis níveis, sendo um acima do ponto médio e os outros cinco em escalas percentis abaixo do ponto médio intrassetorial. 
Ao relacionar os resultados da Análise Discriminante com as classificações obtidas por meio do Isif-Créd, dispostos em cinco categorias (Precária, Baixa, Média, Alta e Excelente Sustentabilidades Financeiras), foram obtidos os seguintes resultados:

Na Análise Discriminante, o Z crítico calculado foi -32,8253. Foi utilizado o método Análise de Correspondência, em que os dados são truncados em inteiros. Assim, foram verificados, nas classificações do Isif-Créd, os valores inferiores a -33 (inclusive) e suas classificações por este indicador. Os resultados são apresentados no quadro 13.

Do total de 1.470 instituições analisadas, a Análise Discriminante classifica 45 delas com Z inferior ao Z crítico. Ao cruzar estas informações, a Análise de Correspondência mostra que 88,9\% dessas instituições haviam sido classificadas como de Baixa ou Precária Sustentabilidade Financeira pelo Isif-Créd. Outros 8,9\%, como sendo de Média Sustentabilidade Financeira e apenas uma $(2,2 \%)$ foi classificadas no grupo de Alta Sustentabilidade Financeira, demonstrando que os dois métodos corroboram nos resultados obtidos.

Quadro 13. Comparação da Classificação Isif-Créd com o ponto de corte da Análise Discriminante, obtido com a Técnica Análise de Correspondência - Insolvência

\begin{tabular}{|l|r|r|r|r|r|r|}
\hline & $\begin{array}{c}\text { Precária } \\
\text { Sustentabilidade } \\
\text { Financeira }\end{array}$ & $\begin{array}{c}\text { Sustentabilidade } \\
\text { Financeira }\end{array}$ & $\begin{array}{c}\text { Sustentabilidade } \\
\text { Financeira }\end{array}$ & $\begin{array}{c}\text { Alta } \\
\text { Sustentabilidade } \\
\text { Financeira }\end{array}$ & $\begin{array}{c}\text { Excelente } \\
\text { Sustentabilidade } \\
\text { Financeira }\end{array}$ & TOTAL \\
\hline Nr. Instituições & 5 & 35 & 4 & 1 & 0 & 45 \\
\hline$\%$ Relativa & $11,1 \%$ & $77,8 \%$ & $8,9 \%$ & $2,2 \%$ & $0,0 \%$ & $100,0 \%$ \\
\hline$\%$ Acumulada & $11,1 \%$ & $88,9 \%$ & $97,8 \%$ & $100,0 \%$ & $100,0 \%$ & \\
\hline
\end{tabular}

Fonte: Resultados da pesquisa.

No outro extremo, com valores superiores a -32 (exclusive), portanto -31, e valores superiores do Z da função Discriminante, foram obtidos os seguintes resultados, que novamente corroboram com as análises do Método Isif-Créd: Somente 13,4\% das instituições classificadas como Precária e Baixa Sustentabilidade têm Z de instituições Solventes. Por outro lado, 41,5\% pertenciam às de Excelente Sustentabilidade e 34,8\% às de Alta Sustentabilidade Financeira, totalizando 76,3\% das instituições com Z crítico de Instituições Solventes ("em atividade), como demonstrado no quadro 14. As demais, não incluídas nestas análises extremas, ficam com indicadores próximos ao ponto de corte Z da Análise Discriminante. 
662 - Sustentabilidade Financeira das Instituições de Microfinanças Brasileiras: Análise das Cooperativas de Crédito Singulares

Quadro 14. Comparação da Classificação Isif-Créd com o ponto de corte da Análise Discriminante, obtido com a Técnica Análise de Correspondência - Solvência

\begin{tabular}{|l|r|r|r|r|r|r|} 
& \multicolumn{1}{|c|}{$\begin{array}{c}\text { Precária } \\
\text { Sustentabilidade } \\
\text { Financeira }\end{array}$} & $\begin{array}{c}\text { Baixa } \\
\text { Sustentabilidade } \\
\text { Financeira }\end{array}$ & $\begin{array}{c}\text { Média } \\
\text { Sustentabilidade } \\
\text { Financeira }\end{array}$ & $\begin{array}{c}\text { Alta } \\
\text { Sustentabilidade } \\
\text { Financeira }\end{array}$ & $\begin{array}{c}\text { Excelente } \\
\text { Sustentabilidade } \\
\text { Financeira }\end{array}$ & TOTAL \\
\hline Nr. Instituições & $\mathbf{5 2}$ & $\mathbf{1 3 4}$ & $\mathbf{1 4 2}$ & $\mathbf{4 8 2}$ & $\mathbf{5 7 5}$ & $\mathbf{1 3 8 5}$ \\
\hline$\%$ Relativa & $\mathbf{3 , 8}$ & $\mathbf{9 , 7} \%$ & $\mathbf{1 0 , 3}$ & $\mathbf{3 4 , 8 \%}$ & $\mathbf{4 1 , 5 \%}$ & $\mathbf{1 0 0 , 0 \%}$ \\
\hline \% Acumulada & $3,8 \%$ & $13,4 \%$ & $23,7 \%$ & $58,5 \%$ & $100,0 \%$ & \\
\hline
\end{tabular}

Fonte: Resultados da pesquisa.

A seguir, apresenta-se outra análise realizada a partir da Regressão Logística.

\subsubsection{Resultados das análises pela regressão logística}

Para a realização das análises pela regressão logística, trabalhou-se com o banco de dados completo, criando, todavia, uma variável aleatória para separação do banco de dados em amostra de desenvolvimento e amostra de validação.

O quadro 15 mostra que a classificação pela regressão logística tem percentual de acerto de $100 \%$, nas duas categorias e nas duas amostras. A amostra de desenvolvimento, com 1.002 instituições "em atividade" e 17 "liquidadas", teve 100\% de acerto e a amostra de validação, com 425 "em atividade" e 13 "liquidadas" também.

Esses resultados foram avaliados a partir do Model Chi-square, que testa a hipótese de que todos os coeficientes da equação são nulos.

Quadro 15. Tabela de Classificação

\begin{tabular}{|c|c|c|c|c|c|c|}
\hline \multirow[b]{4}{*}{ Observed } & \multicolumn{6}{|c|}{ Predicted } \\
\hline & \multicolumn{3}{|c|}{ Selected Cases : a } & \multicolumn{3}{|c|}{ UnselectedCases :b } \\
\hline & \multicolumn{2}{|c|}{ Liquidadas $=0$ Em Atividade $=1$} & \multirow[b]{2}{*}{$\%$ Correct } & \multicolumn{2}{|c|}{ Liquidadas $=0$ Em Atividade $=1$} & \multirow[b]{2}{*}{$\%$ Correct } \\
\hline & 0 & 1 & & 0 & 1 & \\
\hline Step 1 Liquidadas $=0$ e Em Atividae $=10$ & 17 & 0 & 100,0 & 13 & 0 & 100,0 \\
\hline 1 & 0 & 1002 & 100,0 & 0 & 425 & 100,0 \\
\hline Overall Percentage & & & 100,0 & & & 100,0 \\
\hline
\end{tabular}

Fonte: Resultados da pesquisa. 
O valor obtido, 172.889, demonstra que pelo menos uma das variáveis independentes melhora a qualidade preditiva do modelo. Isso é atestado pelo nível de significância $(0,000)$. Assim, rejeita-se a hipótese nula (Ho) de que todos os parâmetros das variáveis explicativas são nulos.

Quadro 16. Teste Chi-square

\begin{tabular}{|r|r|r|c|}
\hline \multicolumn{4}{|c|}{ Omnibus Tests of Model Coefficients } \\
\hline & Chi-square & df & Sig. \\
\hline Step 1 Step & 172.889 & 15 & 0,000 \\
\hline Block & 172.889 & 15 & 0,000 \\
\hline Model & 172.889 & 15 & 0,000 \\
\hline
\end{tabular}

Fonte: Resultados da pesquisa.

Conforme mostram Corrar et al. (2008, p. 294), "uma das principais medidas de avaliação geral da Regressão Logística é o Log Likelihood Value. (...) o nível ideal do Like é zero". Observa-se, no quadro 17, que esse valor foi 0,000 , demonstrando que a regressão como um todo é estatisticamente significante. A análise do desempenho do modelo, pelo teste de Cox \& Snell R Square, que é equivalente ao R-Quadrado da regressão linear, mostra que $15,6 \%$ das variações no $\log$ da razão de chance são explicadas pelas variáveis independentes. Esse índice serve para comparar diferentes modelos. Por sua vez, o Nagelkerke R Square mostra resultado igual a 1.000. Por esse resultado, pode-se concluir que as variáveis independentes podem explicar 100\% da variável dependente (Nageslkerke R Square: escala de 0 a 1).

Quadro 17. Indicadores de Desempenho do Modelo

\begin{tabular}{|c|c|c|c|}
\hline \multicolumn{4}{|c|}{ Model Summary } \\
\hline Step & "-2 Log likelihood" & Cox \&Snell R Square & Nagelkerke R Square \\
\hline $\mathbf{1}$ & $0,000 \mathrm{a}$ & 0,156 & 1,000 \\
\hline a=Estimation terminated at iteration number 20 because maximum \\
\hline \multicolumn{3}{|c|}{ iterations has been reached. Final solution cannot be found. } \\
\hline
\end{tabular}

Fonte: Resultados da pesquisa.

Por outro lado, as variáveis da regressão logística apresentaram nível de significância superior a 10\% e o modelo deixou de ser considerado. 
664 - Sustentabilidade Financeira das Instituições de Microfinanças Brasileiras: Análise das Cooperativas de Crédito Singulares

\subsubsection{Resultados da aplicação do método redes neurais}

Estas estimativas foram feitas com a base de dados correspondente aos dois primeiros quartis, ou seja, para instituições com Ativos Totais até R\$15 milhões. Para tanto, foram trabalhados os dados das 735 cooperativas menores.

O quadro 18 mostra que foram selecionados 510 casos para treinamento e 219 para teste, sendo excluídas seis instituições.

Quadro 18. Sumário dos casos processados pela Rede Neural

\begin{tabular}{|l|c|c|}
\hline & N & Percent \\
\hline Sample Training & 510 & $70,0 \%$ \\
\hline Testing & 219 & $30,0 \%$ \\
\hline Valid & 729 & $100,0 \%$ \\
\hline Excluded & 6 & \\
\hline Total & 735 & \\
\hline
\end{tabular}

Fonte: Resultados da pesquisa.

Conforme mostra o quadro 19, o método Redes Neurais obteve $100 \%$ de acerto, tanto na fase de treinamento quanto no banco de dados de teste.

Quadro 19. Quadro de Classificação do método Redes Neurais para as 50\% menores cooperativas de crédito do Brasil (Ativos Totais até $\mathrm{R} \$$ 15 milhões)

\begin{tabular}{|lc|c|c|c|}
\hline \multicolumn{4}{|c|}{ Classification } \\
\hline Sample & Observed & Liquidadas & Em Atividade & $\%$ Correct \\
\hline Training & Liquidadas & 17 & 0 & $100,0 \%$ \\
\hline & Em Atividade & 0 & 493 & $100,0 \%$ \\
\hline Overall Percent & $3,3 \%$ & $96,7 \%$ & $100,0 \%$ \\
\hline Testing & Liquidadas & 11 & 0 & $100,0 \%$ \\
\hline \multicolumn{7}{|c|}{ Em Atividade } & 0 & 208 & $100,0 \%$ \\
\hline Dependent Variable: Situação de Funcionamento & $95,0 \%$ & $100,0 \%$ \\
\hline
\end{tabular}

Fonte: Resultados da pesquisa. 
Edison Luiz Leismann \& · 665 Charles Ulises de Montreuil Carmona

A seguir, a figura 1 mostra a estrutura de análise do método Redes Neurais, em que $L O A 1=0$ representam as instituições liquidadas e $L O A 1=1$ representam as "em atividade".

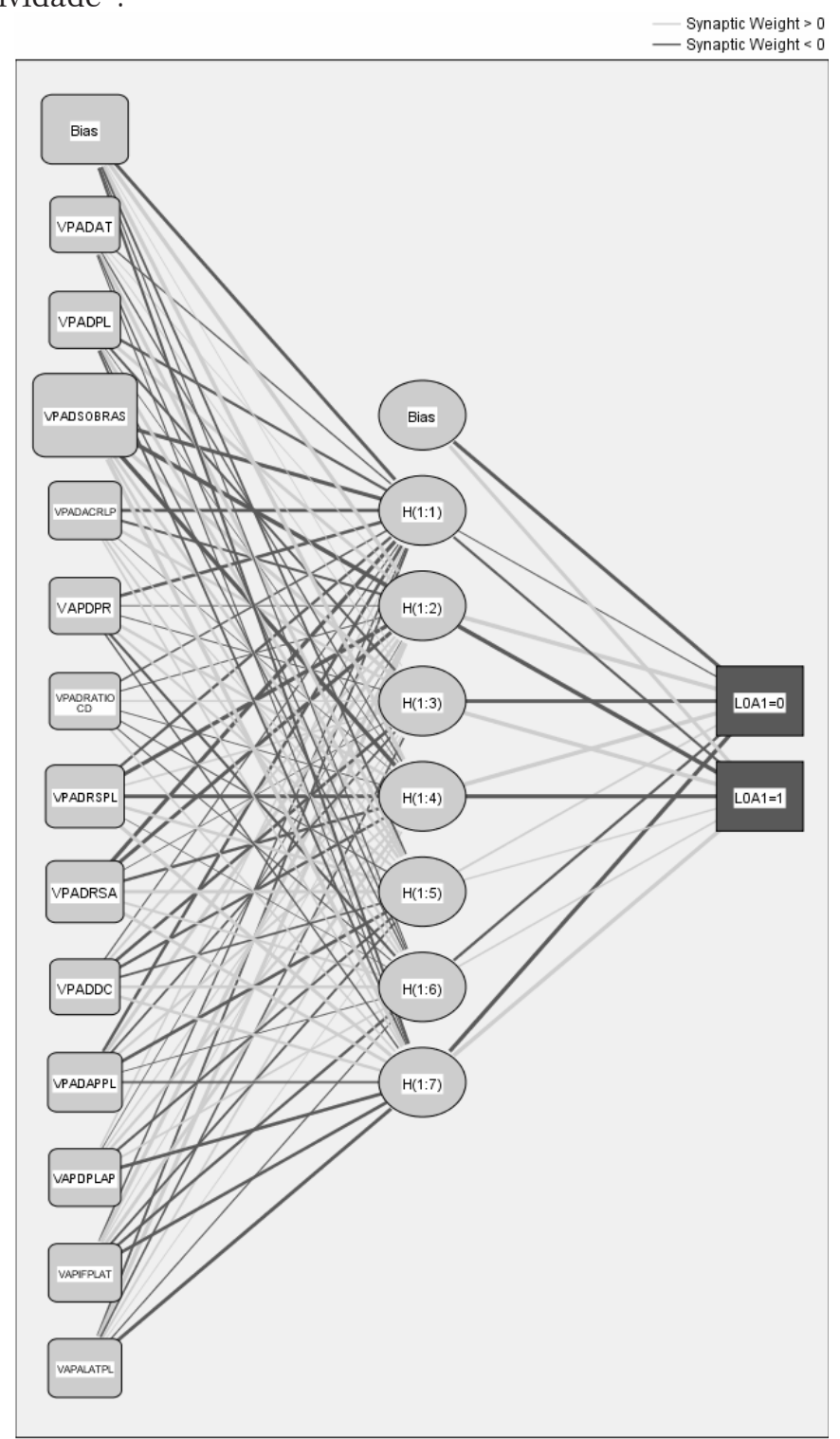

Hidden layer activation function: Hyperbolic tangent

Output layer activation function: Softmax

Figura 1. Estrutura da Rede Neural para as cooperativas de crédito Fonte: Resultados da pesquisa. 
666 - Sustentabilidade Financeira das Instituições de Microfinanças Brasileiras: Análise das Cooperativas de Crédito Singulares

Os coeficientes da estimação Redes Neurais obtidos e a sua importância, são apresentados no quadro 20.

Quadro 20. Importância das variáveis independentes do método Redes Neurais

\begin{tabular}{|l|c|c|}
\hline \multicolumn{1}{|c|}{ Independent Variable Importance } & Importance & Normalized Importance \\
\hline Valor Padronizado do Ativo Total & 0,024 & $4,6 \%$ \\
\hline Valor Padronizado do Patrimônio Líquido (PL) & 0,067 & $12,8 \%$ \\
\hline Valor Padronizado das Sobras & 0,527 & $100,0 \%$ \\
\hline Valor Padronizado do AC+RLP & 0,030 & $5,7 \%$ \\
\hline Valor Padronizado do Patrimônio de Referência & 0,025 & $4,8 \%$ \\
\hline Valor Padronizado do Ratio Contas Credoras/Contas Devedoras & 0,029 & $5,5 \%$ \\
\hline Valor Padronizado do Retorno sobre o Patrimônio Liquido & 0,031 & $5,8 \%$ \\
\hline Valor Padronizado do Retorno sobre o Ativo & 0,066 & $12,6 \%$ \\
\hline Valor Padronizado da Relação Passivo Exigível/Ativo Total & 0,005 & $0,9 \%$ \\
\hline Valor Padronizado da Relação Ativo Permanente/PL & 0,091 & $17,4 \%$ \\
\hline Valor Padronizado da Relação PL/Ativo Permanente & 0,045 & $8,6 \%$ \\
\hline Valor Padronizado da Independência Financeira & 0,011 & $2,2 \%$ \\
\hline Valor Padronizado da Alavancagem Financeira & 0,048 & $9,2 \%$ \\
\hline
\end{tabular}

Fonte: Resultados da Pesquisa.

Como pode ser observado no quadro 20, o Valor Padronizado das Sobras é o item de maior importância para selecionar a variável dependente, com coeficiente 0,527, o maior na coluna da esquerda, com valor de 100\%. Assim, os demais coeficientes são relacionados a este (Normalized Importance).

Comparando esses resultados com os obtidos na Análise Discriminante, tomando-se por base a Equação 15, em que o Valor Padronizado das Sobras e o Valor Padronizado do Retorno Sobre o Patrimônio Líquido foram os selecionados, observa-se que, neste modelo de Redes Neurais, esses mesmos indicadores surgem com importância de 100\% e 5,8\%. A Equação 15 foi obtida com os cálculos do primeiro quartil (Micros). No segundo quartil (Pequenas), além dessas duas variáveis citadas com 100\% e 5,8\% (Figura 20), outras três foram selecionadas pelo método Stepwise, embora estas tenham importância menor no método Redes Neurais: Valor Padronizado da Independência Financeira com 2,2\%; Valor Padronizado do Passivo Exigível/Ativo Total, com 0,9\% e Valor Padronizado do Ativo Circulante mais o Realizável a Longo Prazo, com 5,7\%. Evidencia-se, assim, certa convergência entre as metodologias analisadas.

Observa-se que, sob diferentes formas de estimação, é possível, com os dados disponíveis no sistema de divulgação do Banco Central do Brasil, obter modelos que permitem classificar as cooperativas de crédito em termos de suas sustentabilidades financeiras. Com isso, as centrais destas e os órgãos reguladores podem antever problemas financeiros e buscar soluções que evitem os sempre traumáticos processos de liquidação. 


\section{Conclusões}

Os resultados mostraram que a subdivisão das instituições em quatro grupos a partir dos valores dos ativos e a padronização dos dados melhoraram substancialmente a acurácia do modelo discriminante nas classificações em dois grupos: "liquidadas" e "em atividade".

Os testes estatísticos realizados e as aplicações dos resultados obtidos na Análise Discriminante das Micros cooperativas de crédito e similares para os outros três grupos (Pequenas, Médias e Grandes) demonstraram que a performance de classificação correta se manteve.

Enquanto no modelo inicial as taxas de acerto foram de 99,72\% nas "em atividade" e somente 56,25\% nas "liquidadas", ao subdividir os dados em quartis, as taxas de acerto sobem para $100 \%$ nas "liquidadas" nos quatro quartis e $100 \%, 100 \%, 99,73 \%$ e 98,64\% entre o primeiro ao quarto quartil, respectivamente, nas "em atividade". Esses valores foram obtidos com a aplicação da função discriminante calculada para as "Micros" e depois aplicada nos outros bancos de dados. Ao calcular no banco de dados das "Pequenas", os resultados mostraram $100 \%$ de acerto. Nesta segunda aplicação (segundo quartil: Pequenas), a função discriminante incorpora, pelo método stepwise, além das duas variáveis explicativas anteriores (Sobras e Retorno sobre o Patrimônio Líquido), mais a Independência Financeira, a Relação Dívida/Capitalização e o somatório do Ativo Circulante e o Realizável a Longo Prazo, todos a partir dos seus valores padronizados, como variáveis explicativas selecionadas.

Em síntese, a Análise Discriminante, quanto usada de maneira adequada, considerando-se os aspectos dos testes estatísticos e aplicando-a sobre dados homogêneos, no caso da previsão de insolvência bancária do setor de cooperativas de crédito, mostrou-se um método robusto para a classificação. A proposta é que os indicadores sejam acompanhados e calculados a cada ano, avaliando e corrigindo o ponto de corte, se necessário.

Embora a ênfase tenha sido dada à Análise Discriminante, outros estudos foram realizados com o mesmo banco de dados, como a Regressão Logística, a Classificação intrassetorial por graus de sustentabilidade a partir da subdivisão em percentis (Isif-Cred) e os cálculos a partir do método Redes Neurais. De alguma forma, as metodologias chegam a resultados similares, mas, antes de tudo, demonstram as possibilidades e potencialidades de análises que podem e devem ser feitas neste importante setor econômico para o desenvolvimento econômico urbano e rural, que são as cooperativas de crédito, pela sua importante atuação nas microfinanças do Brasil. 
668 - Sustentabilidade Financeira das Instituições de Microfinanças Brasileiras: Análise das Cooperativas de Crédito Singulares

Um dos limitadores para essas estimativas são sempre a falta de empresas "liquidadas" em quantidade suficiente, em função da necessidade de subdivisão da amostra em duas partes: desenvolvimento e validação. Outro foi o fato de ter trabalhado com dados sintéticos.

Novas pesquisas deverão ser feitas a partir de dados analíticos, que são informados ao Banco Central pelas instituições, mas que não estavam disponíveis para toda população, como analisado nesta pesquisa. Com dados no segundo ou terceiro nível do plano de contas do Demonstrativo de Resultados do Exercício e com os Balanços Patrimoniais, novas pesquisas poderão ser desenvolvidas, incorporando outras variáveis na análise.

\section{Referências Bibliográficas}

AMORIN NETO, A.A.; CARMONA, C.U.M. Modelagem do risco de crédito: um estudo do segmento de pessoas físicas em um banco de varejo. REAd - Edição 40 Vol. 10, nr.4, jul-ago 2004.

ARAÚJO, E.A.; CARMONA, C.U.M. Desenvolvimento de Modelos Credit Scoring com Abordagem de Regressão Logística para a Gestão da Inadimplência de uma Instituição de Microcrédito. Contab. Vista \& Rev., vol. 18, n.3, p-107-131, jul./set. 2007.

BANCO CENTRAL DO BRASIL. www.bcb.gov.br. Acessos entre outubro/2008; abril/2009; janeiro 2010.

BARRY, N. Women's World Banking - Construindo sistemas de financiamento nacional para pessoas de baixa renda, em Apresentação no "I Encontro Internacional Sobre Regulação e Supervisão em Microfinanças". Salvador-BA, Junho, 2005. Disponível no site: www.bcb.gov.br - Acesso em 15/ 03/2008.

BECK, S.; OGDEN, T. Responsabilidade Social-Cuidado com o microcrédito. Harvard Business Review, setembro, 2007.

BERNSTEIN, P.L. \& DAMODARAM, A. Administração de Investimentos. Porto Alegre, Bookman, 2000, 423p.

BIS- Bank International Settlements. Supervisory guidance for assessing banks' financial instrument fair value practices. http://www.bis.org. 
Comitê de Supervisão Bancária de Basiléia (BCBS, sigla de Basel Committee on Banking Supervision). Abril, 2009. Acesso em 19/04/2009.

BREALEY, R.A. \& MYERS, S.C. Finanças Corporativas. Financiamento e Gestão de Risco. Tradução Robert Brian Taylor. Porto Alegre: Bookman, 2005, 552p.

BRUSKY, B. \& FORTUNA, J. P. Entendendo a demanda para as microfinanças no Brasil. Um estudo qualitativo em duas cidades. BNDES, Livreto Microfinanças pmd, 2002.

CARMONA, C.U.M \& LUCENA, P., Risco e Retorno. In:CARMONA, C.U.M. Finanças Corporativas e Mercados. São Paulo, Atlas, 2009, 237p.

CAOUETTE, J.; ALTMAN, E.; NARAYANAM, P. Gestão do risco de crédito: o próximo grande desafio financeiro. Rio de Janeiro: Qualitymark, 1999.

CARVALHO, D.B.; CALDAS, M.P. Basiléia II: abordagem prática para acompanhamento de risco operacional em instituições financeiras. Resenha BM\&F -169, jul/set/2006, p.76 a 84. 2006.

CHRISTEN, R.P.; et al. (1995). "Maximizing the Outreach of Microenterprise Finance: An Analysis of Successful Microfinance Programs". Program and Operations Assessment Report No. 10. Washington DC: United States Agency for International Development (Agência americana para o desenvolvimento internacional).

CORRAR, L.J.; PAUlO, E. \& DIAS FILHO, J.M. Análise Multivariada. FIPECAFI. São Paulo, Atlas, 2007, 541p.

Desenvolvimento Financeiro e o Mecanismo de Transmissão da Política Monetária. PUC-Rio - Certificação Digital Nr. 0512362/CB. (www2.dbd.puc-rio.br / pergamum/tesesabertas/0512362_07_cap_03.pdf)

HELMS, B. \& REILLE, X. Tetos aos juros nas microfinanças: um olhar sobre a questão (setembro/2004). http://www.cgap.org/gm/document -1.9.2651/ OccasionalPaper_09_po.pdf. Acesso em 12 de janeiro de 2010.

HOFFMAN, A.A.; DRUMOND DE MELO, F. Lições de Basiléia I. Banco Central do Brasil, Diretoria de Fiscalização -DEFIS- e Diretoria de Normas DINOR, 2006. www.bcb.br. 
670 - Sustentabilidade Financeira das Instituições de Microfinanças Brasileiras: Análise das Cooperativas de Crédito Singulares

IPEA. Instituto de Pesquisas e Economia Aplicada. www.ipea.org.br , Acesso em setembro/2008.

MINGOTI, S.A. Análise de dados através de métodos de estatística multivariada- Uma abordagem aplicada. Editora UFMG. 2005, 295p.

MONZONI NETO, M.P.; FIGUEIREDO, J.C. Avaliação do Microcrédito Produtivo Orientado na Renda dos Microempreendedores. XXXII Encontro da ANPAD - Rio de Janeiro, 6 a 10 de setembro, 2008. Artigo: APSC 2898.pdf.

MOURA, M.J.S.B.; BUENO, R.L.S.; ROCHA, H.W.P.; MURITIBA, P.M.; MURITIBA, S.N. Características que Levam ao Comportamento Ético: um Estudo dos Agentes de Microcrédito. XXXII Encontro da ANPAD Rio de Janeiro, 6 a 10 de setembro, 2008. Artigo: EORB 1365.pdf.

NICHTER, S.; GOLDMARK, L.; FIORI, A. Entendendo as microfinanças no contexto brasileiro. PDI-BNDES, Livreto Contexto Brasileiro. Pmd. 2002.

OLIVERA, MANGLIO AGUILAR. El financiamiento de las micro y pequeñas empresas em puno. Um análisis empírico de la demanda de créditos. 2004, em Journal Of Savings And Development. http://cies.org.pe/ files/ active/0/pbc0313.pdf, acessos em 15/01/2010.

RELATÓRIO BRUDTLAND - ou Brundtland Report, 1987. http:// www.ace.mmu.ac.uk/eae/Sustainability/Older/Brundtland_Report.html. Acesso em 08 de janeiro de 2010.

PANDELO JUNIOR, D.R. Utilização da Análise Discriminante para Previsão da Insolvência Bancária. - 30 $0^{\circ}$ ENANPAD- 23 a 27 de setembro/ 2006- Salvador/BA, Brasil, 2006. FICA 436 pdf.

Resenha BMF. RISCOS - Depois da Tempestade. Entrevista com Charles Dallara, Diretor do IIF -Instituto de Finanças Internacionais, realizada por Carlos José dias Filho. Jornalista. E-mail:carlosdiasfilho@gmail.com. Nr. 176, Abril, 2009. p.50-54.

ROSENBERG, R. Microcredit Interest Rates. Occasional Paper, Washington, n.1, nov. 2002, p.1-12. Disponível em http://www.cgap.org/gm/document-1.9.2696/ 
OccasionalPaper_01.pdf. Acesso em 20/12/2009.

SANTOS, C.G.; CARRION, R.S.M. Microcrédito e Pobreza: Um Diálogo Possível? XXXII Encontro da ANPAD - Rio de Janeiro, 6 a 10 de setembro, 2008. Artigo: APSC 1523.pdf.

SAUNDERS, A. Administração de Instituições Financeiras. Tradução da $2^{a}$ Edição Americana. Editora Atlas, São Paulo, 2000. 663p.

SELA, V.M.; SELA, F.E.R.; DA COSTA; S.C. A Importância do Microcrédito para o Desenvolvimento Econômico e Social: um estudo sobre as contribuições proporcionadas pelo Banco do Povo de Maringá aos tomadores de microcrédito. XXX Encontro da ANPAD - Salvador-BA-Brasil, 23 a 27 de setembro de 2006. Artigo: APSB 2602.pdf.

SILVA JUNIOR, J.T.; SILVA GONÇALVES, S.M.; CALOU, A.L. Avaliando Experiências de Gestão Social: Os Impactos do Banco Palmas para o Desenvolvimento do Território nos últimos 10 Anos (1998-2007). XXXII Encontro da ANPAD - Rio de Janeiro, RJ-Brasil, 6 a 10 de setembro, 2008. Artigo: APSC 3145.pdf.

SOARES, M. M. Microfinanças - O Papel do Banco Central do Brasil e a Importância do Cooperativismo de Crédito/ Mardem Marques Soares, Abelardo Duarte de Melo Sobrinho. Brasília: BCB, 2007. 170 p.

SPSS - Statistical Package for the Social Sciences. www.spss.com.br

WATERFIELD, C.; RAMSIMG, N. Handbook for management information systems for microfinance institutions. CGAP. Technical Tool Series, n. 1, fev, 1998.

WRIGHT, D. \& ALAMGIR, D. Microcredit Interest Rates in Bangladesh: Capping Versus Competition, Mar, 2004. http:// www.microfinancegateway.org/content/article/detail/23259, acesso em 10 de janeiro de 2010. 